1. Энергетическая стратегия Российской Федерации на период до 2035 года, утв. Распоряжением Правительства Российской Федерации от 9 июня 2020 г. № 1523-p. - Режим доступа: https://www.garant.ru/ products/ipo/prime/doc/74148810/

2. Кожевников, Н.Н. Практические рекомендации по использованию методов оценки экономической эффективности инвестиций в энергосбережение / Н. Н. Кожевников, Н. С. Чинакаева, Е. В. Чернова. - М.: Изд-во МЭИ, 2000. - 132 с.

3. Савина, Н.В. Системный анализ потерь электроэнергии в электрических распределительных сетях: монография. - Новосибирск : Наука, 2008. - 228 с.

4. Грачева, Е.И., Горлов, А.Н., Шакурова, 3.М. Анализ и оценка экономии электроэнергии в системах внутризаводского электроснабжения // Известия высших учебных заведений. Проблемы энергетики. - 2020. - Т. 22 , № 2. - С. 65-74.

УДК 696.6

Артюшевская Екатерина Юрьевна

Амурский государственный университет,

г. Благовещенск, Россия

e-mail: kateona2006@yandex.ru

Artyushevskaya Ekaterina Yurievna

Amur State University,

Blagoveshchensk, Russia

e-mail: kateona2006@yandex.ru

Мясоедов Юрий Викторович

Амурский государственный университет,

г. Благовещенск, Россия

e-mail: myv@amursu.ru

Myasoedov Yuri Viktorovich

Amur State University,

Blagoveshchensk, Russia

e-mail:myv@amursu.ru

Мясоедова Лариса Анатольевна

Амурский государственный университет,

г. Благовещенск, Россия

e-mail: lo.myasoedova@gmail.com

Myasoedova Larisa Anatolievna

Amur State University,

Blagoveshchensk, Russia

e-mail: lo.myasoedova@gmail.com

СПОСОБЫ ЭНЕРГЕТИЧЕСКОЙ САНАЦИИ ЖИЛЫХ ЗДАНИЙ

В УСЛОВИЯХ ХОЛОДНОГО КЛИМАТА

\title{
METHODS OF ENERGY REHABILITATION OF RESIDENTIAL BUILDINGS IN A COLD CLIMATE
}

Аннотация. Определены основные направления повымения энергетической эффективности жсилых зданий в условиях холодного климата. Рассмотрены мероприятия по повышению энергоэффективности наружных ограждающих конструкций, а также по повышению эффективности технических решений и инженерных систем. Установлены наиболее перспективные методы энергетической санации. 
Abstract. The main directions of increasing the energy efficiency of residential buildings in a cold climate are determined. The most effective measures to improve the energy efficiency of external enclosing structures, as well as measures aimed at improving the efficiency of technical solutions and engineering systems, are considered. The most promising methods of energy rehabilitation are established.

Ключевые слова: энергосбережение, энергетическая санация, энергоэффективные мероприятия, энергоресурсы, тепловая энергия, электроэнергия, модернизация здания.

Key words: energy saving, energy rehabilitation, energy-efficient measures, energy resources, thermal energy, electricity, building modernization.

\section{DOI: 10.22250/jasu.93.14}

Комплексная энергетическая санация - это ряд мероприятий. направленных на повышение энергоэффективности здания, - например. утепление фасада, крыши, замена окон, модернизация системы отопления и т.д. Комплексная санация может включать также неэнергосберегающие мероприятия - модернизацию электрооборудования, сантехники или балконов и др.

Энергетическая санация здания способствует повышению уровня комфорта проживания; снижению потребления энергоресурсов населением, что приводит к более низким затратам на коммунальные услуги, росту рыночной стоимости жилого дома за счет улучшения его эстетического вида, а повышение устойчивости здания увеличивает срок эксплуатации жилого дома.

Развитие инновационных технологий в различных сферах экономики, рост числа населения на планете, стремительное развитие ведущих стран - всё это способствует повышению энергопотребления в мировом масштабе. В России наибольшее энергопотребление характерно для обрабатывающей промышленности, второе место по объемам потребления энергоресурсов занимает жилищнокоммунальный сектор. По этой причине проблема снижения потребления энергии при проектировании и эксплуатации зданий остается актуальной.

Повышения энергоэффективности зданий необходимо добиваться с учетом архитектурно-планировочных, организационно-технологических и конструктивных решений как существующих, так и строящихся жилых зданий. Развитие данных направлений зависит от множества факторов, в том числе от экономических, климатических и технических. Основная задача заключается в грамотной оптимизации этих решений на основе анализа основных способов энергетической санации жилых зданий.

В условиях Амурской области повышение энергоэффективности жилых домов позволит значительно снизить потребление энергоресурсов. Для климата области характерен большой перепад температур. На севере области средняя январская температура опускается до $-31^{\circ} \mathrm{C}$, абсолютный минимум $-45,4^{\circ} \mathrm{C}$; на юге средняя температура зимой в диапазоне от $-26^{\circ} \mathrm{C}$ до $-22^{\circ} \mathrm{C}$. Климат характеризуют прежде всего показатели температуры самого холодного и самого теплого месяцев. В летнее время на юге области достаточно тепло, с избыточным увлажнением, температура колеблется от $20^{\circ}$ до $22^{\circ} \mathrm{C}$. Июльские температуры в межгорных долинах севера поднимаются до $16-19^{\circ} \mathrm{C}$. В горных районах температура с высотой достигает $12^{\circ} \mathrm{C}$. Средние абсолютные максимумы температуры на севере области могут достигать $38^{\circ}$, а на юге - до $40^{\circ} \mathrm{C}$. Годовое количество осадков в области велико и составляет от 700 до 1000 мм, причем до 70\% годовой нормы осадков может выпадать в летний период.

Повышение энергоэффективности в жилом комплексе позволит сократить нерациональный расход тепловой энергии, подобрать альтернативные решения. Удельные тепловые потери здания на инфильтрацию нагретого воздуха составляют около 40\%; теплопотери из-за нерационального расхода горячей воды и нерегулируемого отопления - $30 \%$; потери через ограждающие конструкции здания $-30 \%$.

Причинами нерационального расхода энергии являются: большая протяженность тепловых сетей наружных теплотрасс, их недостаточная теплоизоляция; недостача приборов учета и регулиро- 
вания на системе отопления и горячего водоснабжения; отсутствие современных типов котельного оборудования на некоторых предприятиях теплоэнергетики; низкое применение вторичных источников энергии; низкого качества теплоизоляция подвалов, перекрытий, окон, наружных стен; неплотности оконных и дверных блоков; нерегулируемые системы естественной вентиляции

Для предотвращения нерационального расхода тепловой энергии необходима энергетическая. санация с учетом технических, финансовых, социальных факторов жилого комплекса.

Комплексная санация - это модернизация здания в целом. Мероприятия по санации, с точки зрения экономии энергии, состоят из энергетически обязательных и энергетически необязательных. Основные мероприятия по санации жилого здания представлены на рис. 1. Энергетически обязательные мероприятия непосредственно влияют на уровень потребления энергии в здании.

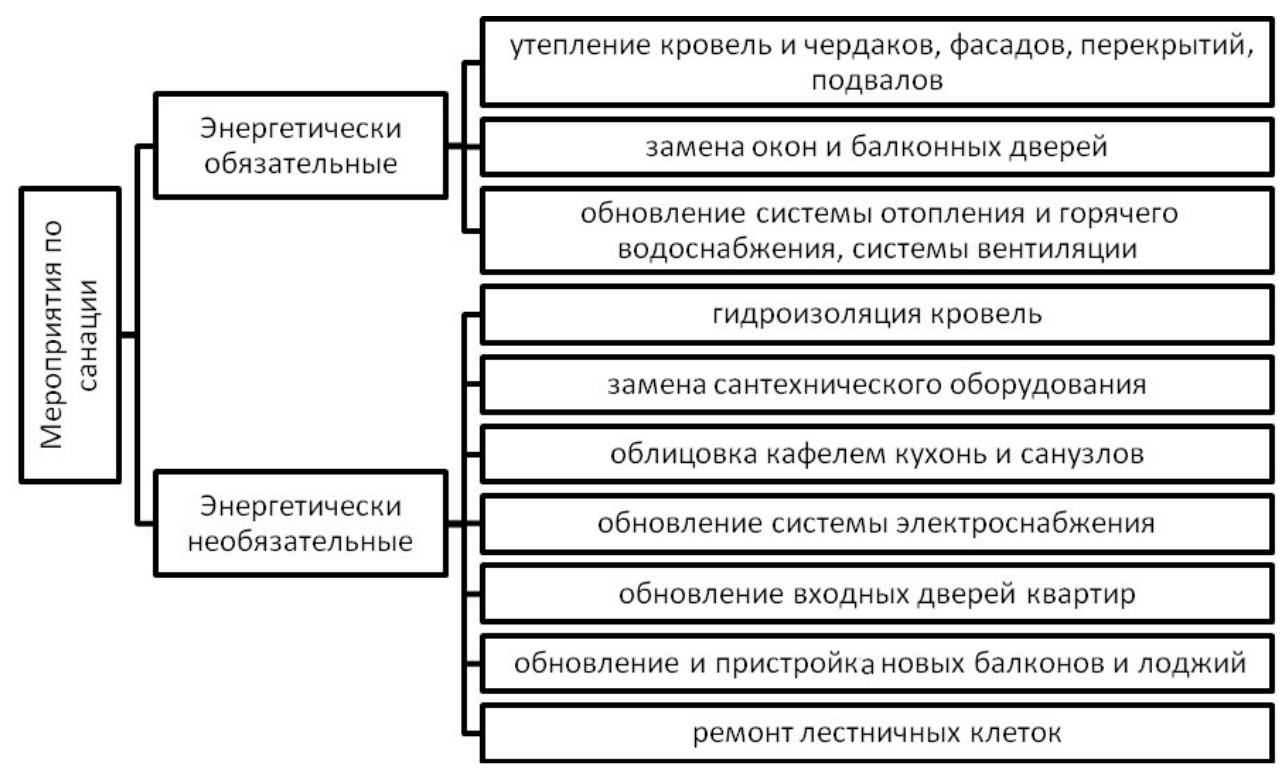

Puc. 1. Мероприятия по санации жилого здания.

В Германии энергетическая санация панельных жилых домов позволила достичь экономии энергоресурсов 30-50\% (в зависимости от материала ограждающих конструкций).

Следовательно, можно выделить два основных направления в области энергетической санации жилых зданий: мероприятия по повышению энергоэффективности наружных ограждающих конструкций и мероприятия, направленные на повышение эффективности технических решений и инженерных систем.

Первые включают в себя утепление или замену окон; утепление наружных стен; утепление покрытий над подвалами; утепление кровли; утепление или замену входных дверей.

Тепловые потери через светопрозрачные ограждающие конструкции (окна) складываются из теплопроводности, конвекции и теплового излучения. Для снижения теплопотерь от теплопроводности и конвекции используют стеклопакеты, но эффект при этом незначителен, основная доля потерь тепла происходит за счет теплового излучения. Для снижения их используют энергоэффективное стекло. Существуют различные виды энергоэффективного стекла: і-стекло, К-стекло, энергосберегающее, теплосберегающее, теплоотражающее, теплопоглощающее и др. Такие стекла позволяют проходить в помещение солнечным коротковолновым излучениям и препятствуют выходу длинноволнового теплового излучения.

Существуют разные варианты модернизации ограждающих конструкций здания энергоэффективными строительными материалами. Чтобы определить наиболее выгодный вариант, необходимо учитывать климатические условия и существующее конструктивное решение здания. Можно выделить два основных варианта утепления ограждающих конструкций: 1) многослойная стена с 
конструктивным слоем и слоем утеплителя; 2) стена, в которой слой утеплителя и конструктивный слой совпадают.

Для теплоизоляции наружных ограждающих конструкций применяются теплоизоляционные плиты из минеральной ваты, конструкции ограждений с экструдированным и вспененным полистиролом в качестве утеплителя, теплоизоляционные плиты, изготовленные из базальтовых горных пород, пеностекло, материалы на основе аэрогеля, изоллат, вакуумные изоляционные плиты, древесноцементные плиты, эковата, керамзит, теплоизоляционная штукатурка, термопена, фибролит, материал Durisol.

Оптимальным вариантом утепления ограждающей конструкции с точки зрения влагообмена является утепление наружной стороны здания. В этом случае большая часть ограждающей конструкции будет иметь положительную температуру. Кроме того, система наружного утепления позволит защитить ограждающую конструкцию от осадков, ветра, перепадов температур, водного конденсата. Утепление стен - одно из эффективных мероприятий при реконструкции существующих зданий для повышения теплозащитных характеристик стен [1].

По некоторым подсчетам грамотное комплексное утепление ограждающих конструкций позволяет сократить расходы на отопление здания на 30-70\% .

Мероприятия, направленные на повышение эффективности технических решений и инженерных систем, можно разделить на два варианта: первый - повышение эффективности непосредственно систем, второй - разумное потребление энергоресурсов, с контролем их расхода для нужд жителей.

Одним из энергосберегающих направлений для экономии энергетических ресурсов является повышение эффективности работы системы отопления. Прежде всего предлагается использовать поквартирные системы отопления, позволяющие обеспечивать возможность учета тепла для каждой квартиры. Экономия, обеспечиваемая этими системами, может достигать $10 \%$ за счет более рационального расхода тепла на отопление помещений. Повышение энергоэффективности систем отопления связано также с применением комнатных контроллеров. Это устройство позволяет понижать температуру воздуха в помещениях, снижать потребность в отоплении в нерабочее время. Во время отсутствия потребителей в квартире можно понижать температуру на $2-3^{\circ} \mathrm{C}$. Экономия энергии - до $8-10 \%$.

Мероприятия по энергоэффективному освещению позволят достичь экономии электроэнергии от $15-40 \%$ за счет применения систем освещения помещений общего пользования на основе энергосберегающих ламп, оснащенных датчиками движения. Данные мероприятия с экономической точки зрения являются низкозатратными.

Важное условие комфортного проживания - наличие качественной вентиляции. Эффективный способ - применение поквартирной или централизованной механической системы вентиляции с утилизацией теплоты вытяжного воздуха. Установлено, что эффективность утилизации может достигать 80\%. Системы гибридной вентиляции - еще одна из эффективных установок. Гибридная вентиляция - вентиляция, в холодный и переходный период года работающая как естественная за счет гравитационного и ветрового напора, а в теплый период года движение воздуха обеспечивается механическими устройствами. Экономия при ее применении достигает $20 \%$. Данная система работает преимущественно в периоды, когда температура наружного воздуха поднимается выше $+5^{\circ} \mathrm{C}[2]$.

Значительно повысить эффективность механической вентиляции можно за счет утилизации теплоты вытяжного воздуха либо для подогрева приточного, либо посредством теплонасосных установок.

Энергетическое обследование необходимо для оценки эффективности использования энергетических ресурсов и снижения расходов на энергообеспечение потребителей, для контроля качественного энергоснабжения и рационального расходования ресурсов. Энергетическая санация позво- 
лит не только на длительный срок улучшить условия проживания и техническое состояние жилого дома, но и сэкономить энергию, ресурсы, сократить энергетические потери.

1. Захаров, А.В. Энергоэффективные конструкции в строительстве: электрон. учеб. пособие / А.В. Захаров, Е.Н. Сычкина, А.Б. Пономарев. - Пермь: Изд-во Перм. нац. исслед. политехн. ун-та, 2017. - 103 с - № 1 .

2. Табунщиков, Ю.А. Энергоэффективные здания и инновационные инженерные системы // АВОК. - 2014.

3. Ушаков, К.В. Повышение энергоэффективности зданий в Российской Федерации // Международный журнал гуманитарных и естественных наук. - 2020. - №7-2. - С. 122-125.

4. Цопа, Н.В. Анализ основных способов проведения энергетической санации в жилых зданиях // Строительство и техногенная безопасность. - 2018. - №11 (63). - С. 67-68.

5. Лысёв, В.И., Шилин, А.С. Направления повышения энергоэффективности зданий и сооружений // Холодильная техника и кондиционирование. - 2017. - № 2. - С. 18-25.

УДК 620.91

\author{
Артюшевская Екатерина Юрьевна \\ Амурский государственный университет, \\ г. Благовещенск, Россия \\ e-mail: kateona2006@yandex.ru \\ Artyushevskaya Ekaterina Yurievna \\ Amur State University, \\ Blagoveshchensk, Russia \\ e-mail: kateona2006@yandex.ru
}

\title{
АНАЛИЗ ПОТЕНЦИАЛА АЛЬТЕРНАТИВНЫХ ИСТОЧНИКОВ ЭНЕРГИИ В РЕСПУБЛИКЕ САХА (ЯКУТИЯ)
}

\section{ANALYSIS OF THE POTENTIAL OF ALTERNATIVE SOURCES ENERGY IN THE REPUBLIC OF SAKHA (YAKUTIA)}

Аннотация. Определен потенциал применения альтернативных источников на территории Республики Саха (Якутия). Произведена оценка действующих источников альтернативной энергии, с учетом плановой экономии топлива. Определены преимущества и предпосылки развития «зеленой энергетики» на территории Республики Саха (Якутия).

Abstract. The potential of using alternative sources in the territory of the Republic of Sakha (Yakutia) is determined. The assessment of the existing alternative energy sources, taking into account the planned fuel economy, was made. The advantages and prerequisites for the development of "green energy" in the territory of the Republic of Sakha (Yakutia) are determined.

Ключевые слова: возобновляемые источники энергии, энергоэффективность, энергосбережение, «зеленая энергетика», солнечная энергия, ветроэнергетика, энергоресурсы.

Key words: renewable energy sources, energy efficiency, energy saving, "green energy", solar energy, wind energy, energy resources.

\section{DOI: 10.22250/jasu.93.15}

Актуальным в современном мире становится переход на экологически чистые источники энергии. Это связано не только с растущим экологическим загрязнением окружающей среды и стрем- 